Received:

$15-\mathrm{XII}-2019$

Accepted:

$22-\mid-2020$

Published Online: 20-II-2020

\section{Corrective Treatment of Ectopic Eruption of Permanent First Molars:} Case Report

\section{Tratamiento correctivo de erupción ectópica de primeros molares}

\section{permanentes: Reporte de casos}

Natalia Gutiérrez Marín DDS1

1. Profesora asociada Departamento de Odontopediatría, Universidad de Costa Rica, Costa Rica.

Correspondence to: Dra. Natalia Gutiérrez Marín - natalia.gutierrez@ucr.ac.cr

ABSTRACT: Ectopic eruption of a tooth is the process in which a tooth emerges in an abnormal position. The first permanent molar is the tooth that most frequently presents ectopic eruption, mostly because it is retained below the distal contour of the second temporary molar. The ectopic eruption may be reversible or irreversible, the latter of which requires corrective treatment to achieve correct eruption of the permanent molar in the arch. Treatments can be minimally invasive, such as the use of interproximal wedging, or more invasive orthodontic devices, such as brass wire, k-loops, Halterman devices, or wedging springs. The aim of this case report is to present two clinical cases where the ectopic eruption of permanent first molars is corrected using elastic separators. Conclusion:The elastic separators could be used successfully in cases of moderate or severe ectopic eruptions, not only in mild cases, as reported in most of the literature. The use of this technique does not require great cooperation from the patient, and it is low in cost.

KEYWORDS: Tooth eruption; Ectopic; Molar; Pediatric dentistry. 
RESUMEN: La erupción ectópica de un diente es el proceso por el cual el diente emerge en una posición anormal. La primera molar permanente es el diente que más frecuentemente presenta erupción ectópica, ya que, en su proceso de erupción, queda retenida debajo del contorno distal de la segunda molar temporal. La erupción ectópica puede ser reversible o irreversible, si es irreversible requiere tratamiento correctivo para lograr que la molar permanente erupciones correctamente en el arco. Los tratamientos pueden ser poco invasivos como el uso de separados elásticos 0 más invasivos con aparatos ortodóncicos tales como brass wire, k-loop, Halterman 0 wedging spring. El objetivo del presente artículo es presentar dos casos clínicos donde se corrige la erupción ectópica de primeros molares permanentes utilizando separadores elásticos. Conclusión: Ios separadores elásticos pueden usarse con éxito en casos de erupciones ectópicas moderadas o severas, no sólo en casos leves como reporta la mayoría de la literatura. El uso de esta técnica no requiere gran cooperación por parte del paciente y es de bajo costo económico.

PALABRAS CLAVES: Erupción dental; Ectópico; Molar; Odontología pediátrica.

INTRODUCTION

Ectopic eruption of a tooth refers to the process in which a tooth emerges in an abnormal position. The teeth that most frequently present ectopic eruptions are the first permanent molars and upper canines, followed by the mandibular canine, the second mandibular premolar, and the upper lateral incisors (1).

The ectopic eruption of a permanent first molar is characterized by the retention of the permanent tooth under the contour of a second temporary molar (2).

The factors associated with ectopic eruption are a shorter length of the maxilla, a position of the maxilla posterior to the base of the skull, and delayed calcification of the permanent molars or abnormal angulation of the eruption of the first permanent molars (3). Also, when a second temporary molar is exfoliated prematurely, there is a significant loss in the dental arch, which may cause mesialization and rotation of a permanent molar (4).
Ectopic eruption of a permanent molar may lead to some consequences like root resorption of the adjacent temporary molar, loss of the length of the arch, inadequate space for the eruption of the surrogate premolar, malocclusions, or neuralgic pain $(3,5,6)$.

The ectopic eruption of a permanent first molar is both a clinical and a radiographic diagnosis. The ideal period to treat this eruption disturbance is between 6 and 8 years old, when the first permanent molar has an incomplete root formation and the second permanent molar is not ready to erupt. The earlier the diagnosis is made, the greater the chances of promoting the development of a stable occlusion (7).

Traditionally, different techniques have been used to correct the ectopic eruption of a permanent molar. Among the most used are interproximal wedging, extraction of the temporary molar and subsequent placement of a space regulator, and orthodontic appliances such as brass wire, k-loops, Halterman devices, or wedging 
springs. The complexity and success of the different techniques vary according to the case and the patient's cooperation (4).

AIM

The purpose of the present study was to report two clinical cases where the ectopic eruption of permanent first molars was corrected using elastic separators.

\section{CASE REPORT}

\section{CASE I}

JAAS is a 7year and 8 month old healthy boy with no history of systemic diseases or trauma. The child went to the dental office for a review. After performing the clinical examination, it was observed that the first permanent molars were all present except the right upper molar, which only showed the distal part of the occlusal face.

In the panoramic radiograph, the first right upper permanent molar with severe ectopic eruption is observed below the distal contour of the second temporary molar. There is great reabsorption of the distal root of the temporary molar, which has no mobility (Fig. 1).

To correct the ectopic eruption of the permanent molar, a 4-mm elastic separator (Ormco $^{\mathrm{TM}}$, California, USA) was placed between the molars. The separator was used for a period of 5 months, with monthly replacement because it softened over time, reducing the pressure exerted on the permanent molar (Fig. 2). The placement of the separator produced slight pain in the patient, but once placed, the patient did not present pain or discomfort. The child's mother was advised that he must maintain good oral hygiene habits.

After 6 months, it was possible to correct the ectopic position of the permanent molar, keeping in the mouth the second temporary molar, which despite the great reabsorption of the distal root did not present mobility, sensitivity, or pain (Fig. 3).

The patient was given control for one year. The first permanent molar remained in good position. The second temporary molar is asymptomatic (Fig. 4).
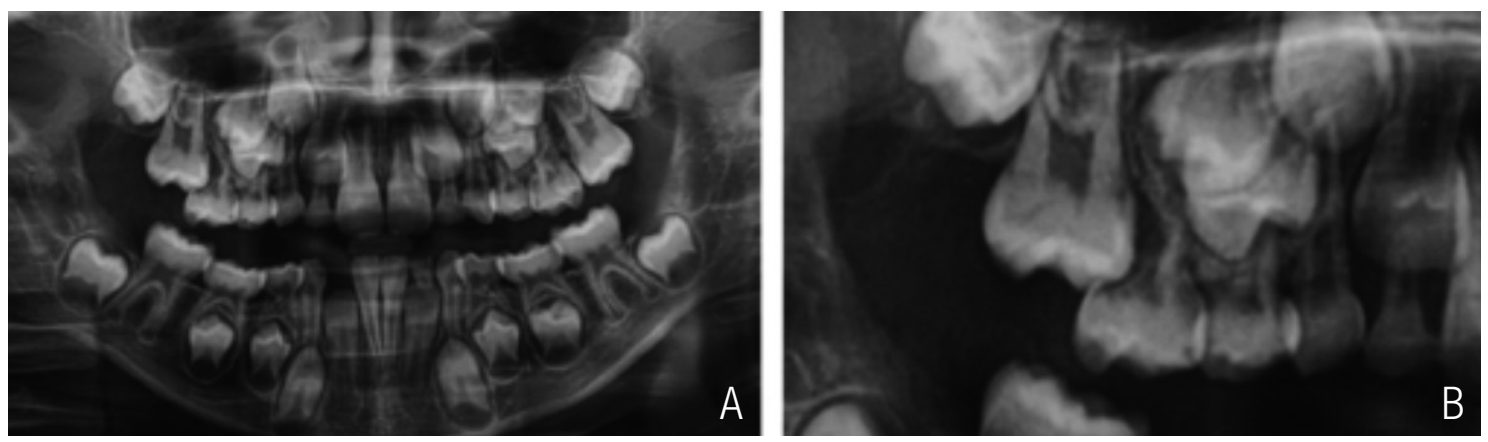

Figure 1. A. Panoramic radiograph: ectopic eruption of upper right first permanent molar. B. Great resorption of the distal root of the second temporary molar. 

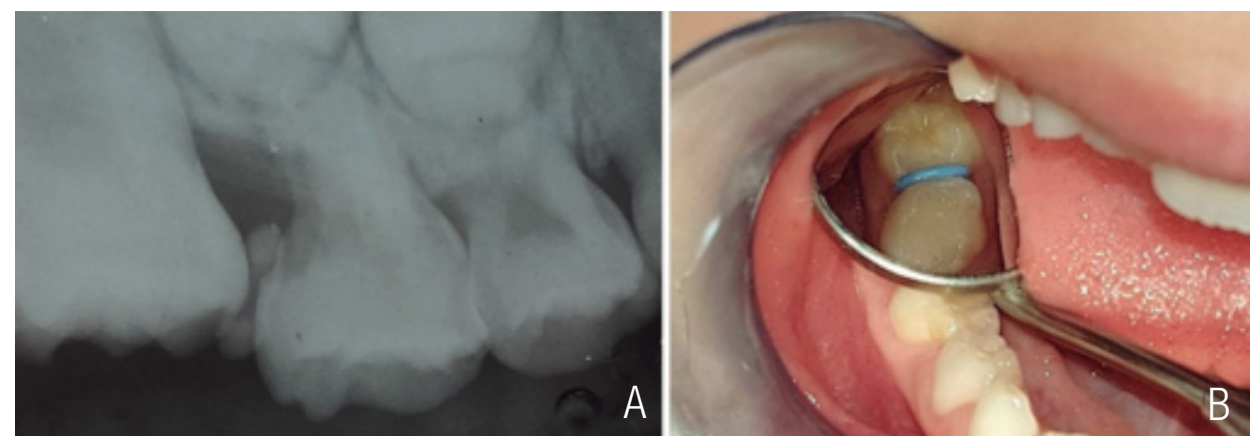

Figure 2. A. Placement of the elastic separator between the molars. B. Second placement of the elastic separator 1 month later.
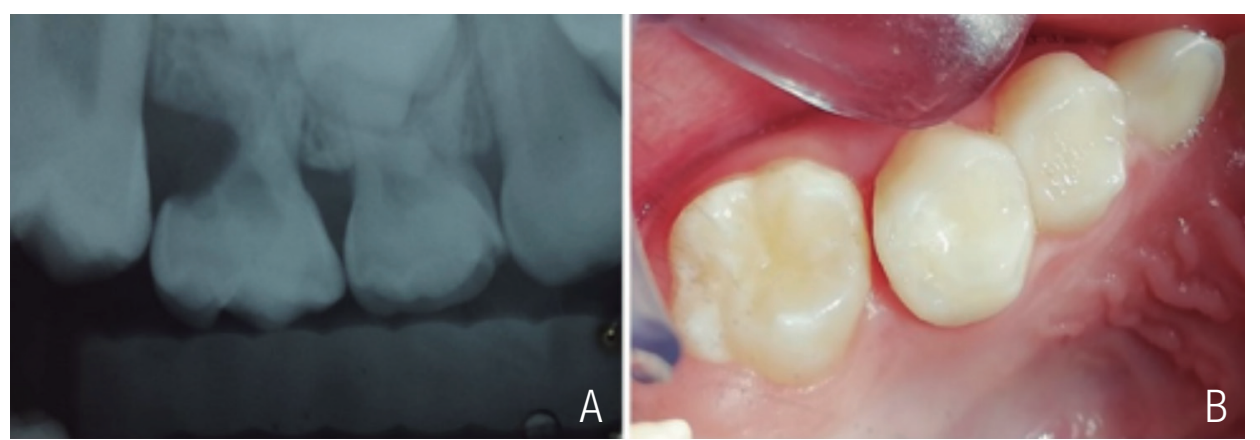

Figure 3. a. Periapical radiograph showing permanent molar in proper position and external reabsorption of distal root of the temporary molar. b. Permanent molar erupted in correct position.

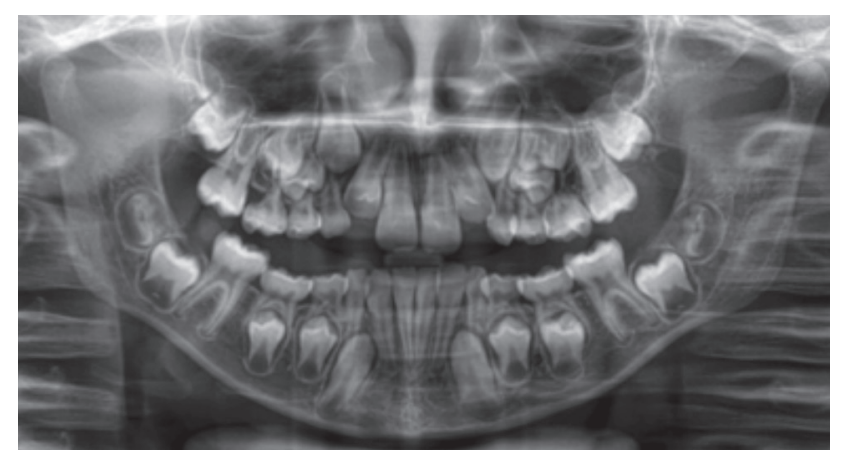

Figure 4. Control x-ray one year later. 


\section{CASE ॥}

LQM is an 8 year old girl, healthy, with no history of dental trauma or systemic diseases. In the clinical examination, it was observed that the first lower permanent molars presented eruption problems, since the mesial part of the occlusal face was not shown.

In the panoramic radiograph, both first lower permanent molars were observed with ectopic eruption below the distal contour of the second temporary molars. Both permanent molars had a moderate ectopic eruption. No reabsorption of the distal root of any temporary molar was observed (Fig. 5.)

Four-millimeter elastic separators (Ormco ${ }^{\mathrm{TM}}$, California, USA) were used to correct the ectopic eruption of the permanent molars. The separators were placed on each molar for a period of 4 months, making replacements every month (Figs. 6a, 6b, 7a, and 7b). The placement of the separator caused a little discomfort in the patient. The mother was told that the girl should maintain very good oral hygiene habits to avoid gingival inflammations in the area.

After 4 months, a correct eruption of both permanent molars was achieved. Once both permanent molars had erupted, it was decided to place sealant on the pits and fissures (Figs. 8a, 8b, 8c, and 9).

In both cases, the parents of the patients gave their written free and informed consent for the publication.
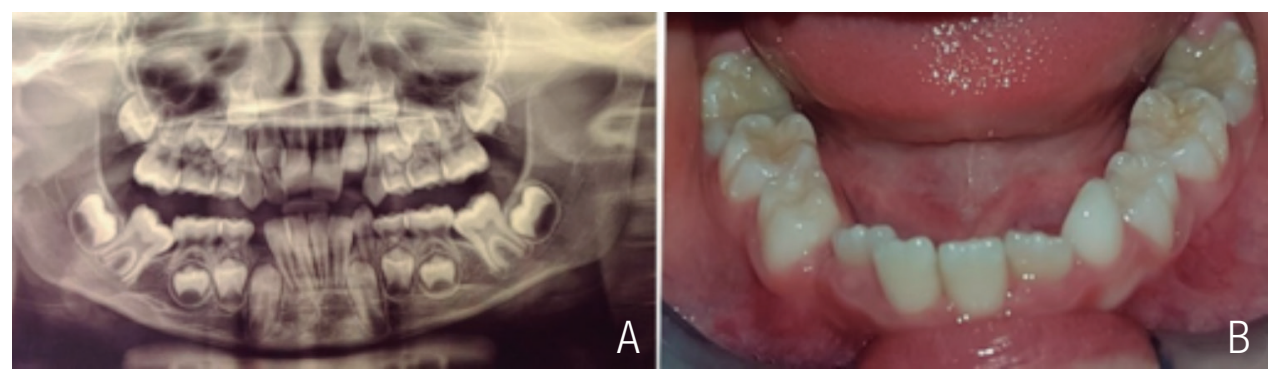

Figure 5. a. Panoramic radiograph: ectopic eruption of lower permanent first molars. b. Ectopic eruption of lower permanent first molars.
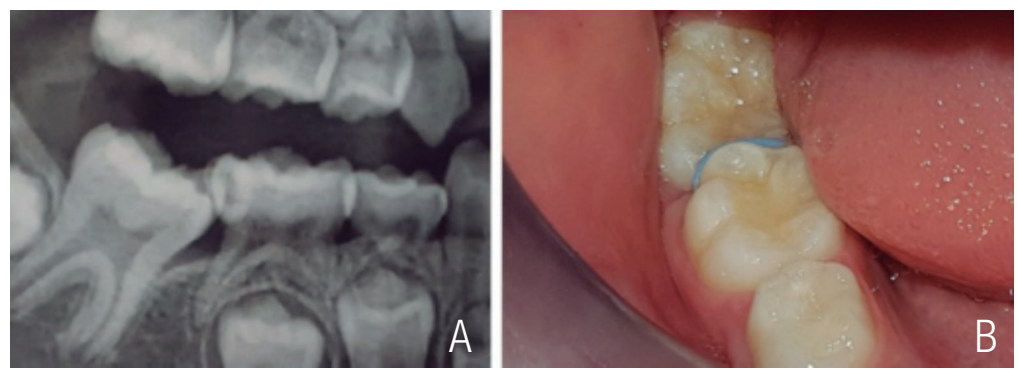

Figure 6. a. Radiographic and b. clinical appearance the day of the placement of the elastic separators on first permanent right molar. 

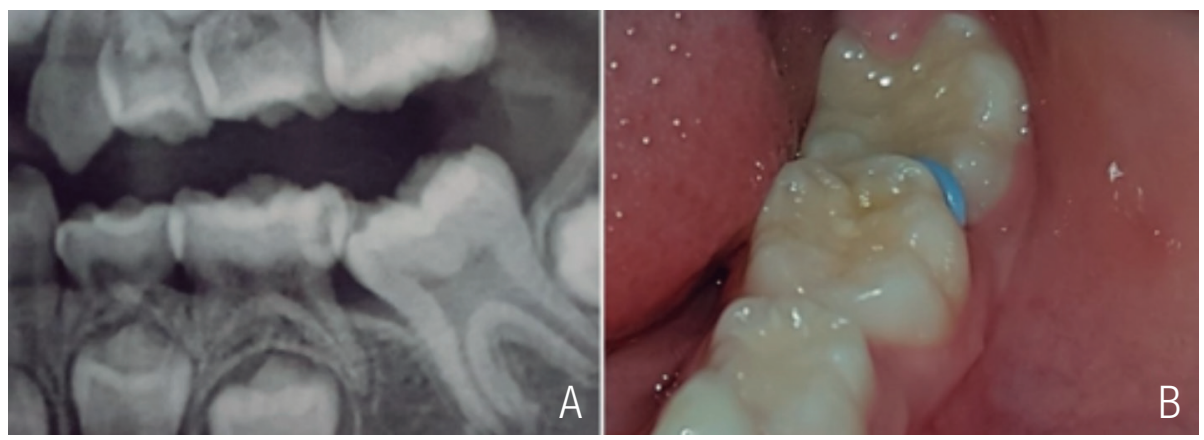

Figure 7. a. Radiographic and b. clinical appearance the day of the placement of the elastic separators on first permanent right molar.
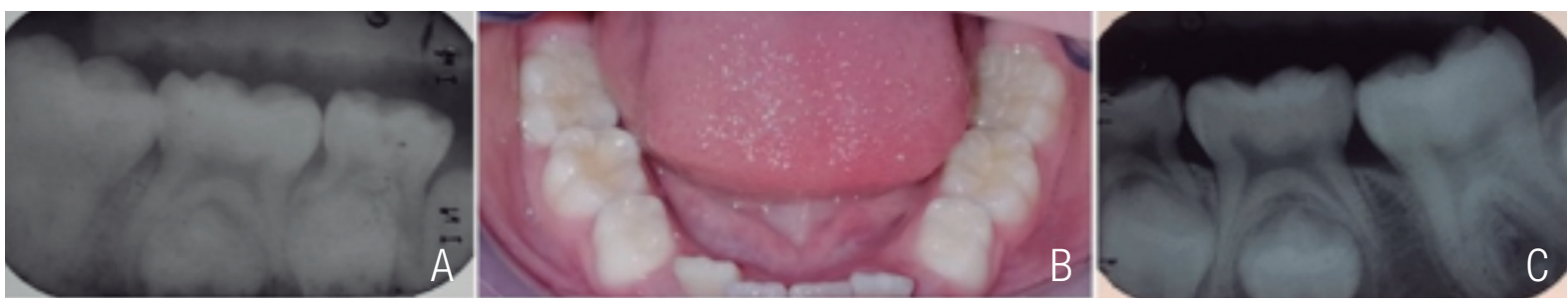

Figure 8. a., b. and c. Permanent molars erupted in correct position.

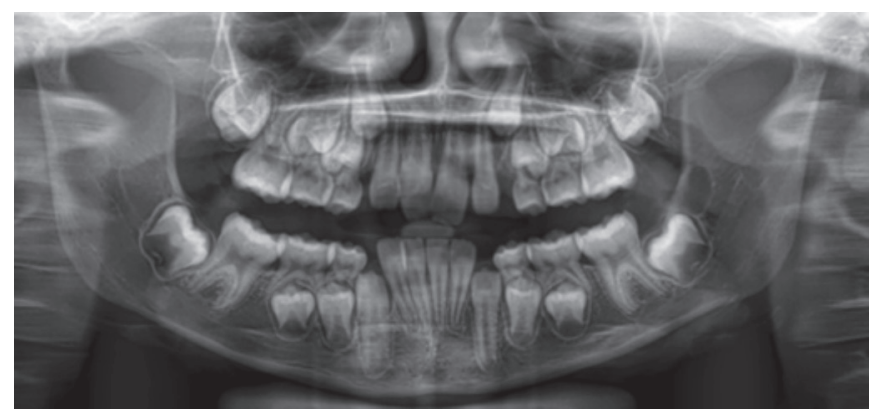

Figure 9. Control x-ray one year later.

\section{DISCUSSION}

The first permanent molar is the tooth that most commonly presents ectopic eruptions, with a prevalence ranging from $2 \%$ to $6 \%$ worldwide $(1,8)$.

Two types of ectopic eruptions have been reported: one reversible and the other irreversible. The reversible type occurs when the ectopic molar is in a position below the distal surface of the second temporary molar, but in the process of eruption, it is unblocked and enters occlusion. The irreversible, as in the clinical cases cited above, occurs when the permanent molar is blocked below the distal contour of the second temporary molar until the temporary molar is exfoliated or receives treatment to correct its eruption process (2). Irreversible ectopic eruptions occur in $40 \%$ of cases (6). 
The types of treatment are divided into two categories: interproximal wedges for mild impaction cases and distal inclination for moderate to severe cases $(1,9)$. The interproximal wedging can be made of copper wire or an elastic separator. The elastic separators come in two sizes: $3 \mathrm{~mm}$ in diameter and $0.75 \mathrm{~mm}$ thick or $4 \mathrm{~mm}$ in diameter and $1 \mathrm{~mm}$ thick (10). In cases of moderate to severe impaction of the first permanent molar, the distal inclination is made with different devices: open-coil springs, brass wire, k-loops, Halterman devices, or wedging springs. These devices are used with or without the extraction of the temporary molar $(3,11,12)$.

In the cases presented, it was decided to use elastic separators, since, as indicated above, the literature reports their use, but their effectiveness is not widely demonstrated in clinical reports. Only two clinical cases were found: one where its effectiveness was demonstrated in a first molar permanent superior, and another corresponding to a second lower permanent molar (10).

In addition, the treatment with elastic separators has many advantages: It is a low-cost technique, it demands minimal time in the chair, and it does not require great cooperation from the patient. Also, it is not necessary to take impressions or perform laboratory work; it is not necessary to apply local anesthesia; there is no deterioration in the permanent molar, as can happen when an orthodontic band is placed; nor can damage occur to the patient in case the separator is detached and ingested (10). During the treatment, none of the patients presented discomfort or oral hygiene problems, and it turned out to be a very convenient technique to use in children, since the children were not required to collaborate in maintaining appliances in the mouth, as happens with the rest of the techniques that require orthodontic implements.

The results were successful in both cases. The permanent molars corrected their position and managed to erupt correctly in the arch, keeping the temporary molars in the mouth. Nevertheless, there was a difference in the duration of the treatments. The literature reports that distalization of lower molars presents greater difficulty than that of higher molars $(13,14)$. However, in the cases reported, it took less time to correct the lower molars' position than that of the upper molar. This could be explained by the difference in the degree of severity of the cases. The lower molars had a moderate ectopic eruption, whereas that of the upper molar was severe.

\section{CONCLUSION}

The elastic separators could be used successfully in cases of moderate or severe ectopic eruptions, not only in mild cases, as reported in most of the literature. The use of this technique does not require great cooperation from the patient, and it is low in cost.

\section{COMPLIANCE WITH ETHICAL STANDARDS}

Conflict of interest All authors declare that they have no conflict of interest.

Ethical approval All procedures performed in studies involving human participants were in accordance with the ethical standards of the institutional and/or national research committee and with the 1964 Helsinki declaration and its later amendments or comparable ethical standards.

Informed consent Informed consent was obtained from all individual participants included in the study.

\section{REFERENCES}

1. Barberia-Leache E., Suarez-Clúa M. C., Saavedra-Ontiveros D. Ectopic eruption of the maxillary first permanent molar: Characteristics and occurrence in growing children. Angle Orthod. 2005; 75 (4): 610-5. 
2. Dabbagh B., Sigal M. J., Tompson B. D., Titley K., Andrews P. Ectopic Eruption of the Permanent Maxillary First Molar: Predictive Factors for Irreversible Outcome. Pediatr Dent. 2017; 39 (3): 215-8.

3. Yaseen S., Naik S., Uloopi K. Ectopic eruption - A review and case report. Contemp Clin Dent. 2011; 2 (1): 3.

4. Kim Y. H., Park K. T. Simple treatment of ectopic eruption with a triangular wedging spring. Pediatr Dent. 2005; 27 (2): 143-5.

5. Thakur S., Thakur N., Gupta S. Innovative chairside technique for the correction of ectopically erupting permanent first molar. Dent Hypotheses. 2014; 3 (3): 115.

6. Becktor K. B., Steiniche K., Kjær I. Association between ectopic eruption of maxillary canines and first molars. Eur J Orthod. 2005; 27 (2): 186-9.

7. Kupietzky A., Soxman J. A. Ectopic eruption of maxillary first permanent molar. Handb Clin Tech Pediatr Dent. 2015; 107-19.

8. Baron C., Houchmand-Cuny M., Enkel B., Lopez-Cazaux S. Prevalence of dental anomalies in French orthodontic patients: A retrospective study. Arch Pediatr [Internet]. 2018; 25 (7): 426-30. Available from: https:// doi.org/10.1016/j.arcped.2018.07.002
9. Kupietzky A. Correction of ectopic eruption of permanent molars utilizing the brass wire technique. Pediatr Dent [Internet]. 2000; 22 (5): 408-12. Available from: http://www. ncbi.nlm.nih.gov/pubmed/11048311

10. Cerny R. Jumbo separators for partial molar impactions. J Clin Orthod [Internet]. 2003; 37 (1): 33-5. Available from: http:/www. scopus.com/inward/record.url?eid=2-s2.0$0038283080 \&$ partnerID $=40 \&$ md $5=8 b 56 c 49$ e2a9c4ac7ade2bf4f4f735130

11. Kennedy DB. Management of an ectopically erupting permanent mandibular molar: a case report. Pediatr Dent. 2008; 30 (1): 63-5.

12. Nam O. H., Ahn H. J., Kim M. S., Park J. H. Treatment of Ectopic Permanent Maxillary First Molar Using a K-loop. J Clin Pediatr Dent. 2015; 39 (4): 387-91.

13. Souki B., Cheib P., de Brito G., Pinto L. M.C. Maxillary second molar impaction in the adjacent ectopic third molar: Report of five rare cases. Contemp Clin Dent. 2015; 6 (3): 421.

14. Young. T. C., Kim. Y. J., Yang. K. S, Lee. D. Y. Bone availability for mandibular molar distalization in adults with mandibular prognathism. Angle Orthod. 2018; 88 (1): $52-7$. 